\title{
Genetic Divergence of Balam Rice (Oryza sativa L.) Germplasm of Bangladesh
}

\author{
MS Ahmed ${ }^{1 *}$, S Parveen ${ }^{2}$, M K Bashar ${ }^{3}$ and A K M Shamsuddin ${ }^{4}$
}

ABSTRACT

\begin{abstract}
Forty genotypes of Balam rice germplasm of Bangladesh were studied for 17 morphophysicochemical characters at BRRI during 2009-11. The cluster analysis using Mahalanobis' $\mathrm{D}^{2}$ statistics, grouped the genotypes into seven clusters, where no duplicate germplasm was found for the studied characters. The highest number of genotypes (8) was constellated into clusters I, III and V and the lowest (2) was in cluster IV. The intraand inter-cluster distances were maximum (1.17 and 21.16) in cluster VII and between clusters II and IV and minimum (0.27 and 2.23) in cluster IV and between clusters II and VII respectively. Based on the values of principal component score, the two-dimensional scatter diagram $\left(Z_{1}-Z_{2}\right)$ also distributed the genotypes into seven groups. The genotype of cluster IV, produced the highest flag and penultimate leaf area $\left(1136 \mathrm{~cm}^{2}\right)$, culm diameter (7.2 mm), days to maturity (152 days), primary and secondary branches per panicle (63), grain yield per panicle $(4.9 \mathrm{~g}), 1000$-grain weight $(29.3 \mathrm{~g})$, grain yield per hill (31.3 g), cooking time (19 $\mathrm{min})$ and amylose content $(24.1 \%)$. Similarly, the genotype of cluster I, produced the tallest plant $(148 \mathrm{~cm})$, maximum straw yield per hill $(40.0 \mathrm{~g})$ and protein content $(9.6 \%)$, while the genotype of cluster VI, produced the highest panicle per plant (21) and the genotype of cluster III, produced the longest grain $(8.8 \mathrm{~mm})$. Therefore, it may be possible to obtain the highest mean values for the maximum studied characters, if the genotypes of cluster IV are crossed with the genotypes of cluster I, cluster III and cluster VI respectively. Besides, the canonical variate analysis showed that the grain length, cooking time, straw yield per hill, days to maturity, plant height and grain yield per panicle contributed maximum to the genetic divergence of the studied germplasms. Finally, the study revealed that the Balam rice germplasm can offer a diverse valuable gene reservoir to utilize in hybridization programmes for the improvement of Balam rice.
\end{abstract}

Key words: Genetic divergence, Balam rice, Bangladesh

\section{INTRODUCTION}

Balam is an indigenous landrace varieties developed over time, by adaptation to its natural and cultural environment and is used to grown in the southern regions especially in Barisal district of the country. Among the fine varieties, Balam tops the list and was known as 'Bashool Balam'. Because it was so fine that it could percolate through one's nose, hence they called it 'Bashool'. There was a time, when Balam used to be cultivated in huge acres of farmland but now gradually leading to extinction and lost their commercial value in the wake of huge demand for high yielding modern rice. As a result, Balam, once adored throughout the subcontinent, was included in the extinct list of
Bangladesh Rice Research Institute (BRRI), with the strains now only preserved in the Gene bank.

Rice germplasm is not only endowed with genetic diversity but also represents a wealth of valuable genes (Sarma et al., 2003). Exploring diversity in a landrace collection is very important for identifying new genes and further improvement of the germplasm (Jayamani et al., 2007). However, Bangladesh had abundant rice germplasms from time immemorial. But, now rice diversity in Bangladesh is threatened all over the country due to extensive cultivation of modern varieties (MVs) along with various intervention of rice habitat (Ahmed et al., 2010). Rice germplasm need to be utilized for maintaining its diversity in rice field.

${ }^{1}$ PSO, GRSD, BRRI, Gazipur 1701. ${ }^{2 S S O}$, TD, BRRI, Gazipur ${ }^{3}$ Country Manager, Harvest Plus, CIAT, Banani, Dhaka 1213, Bangladesh. ${ }^{4}$ Professor, Department of Genetics and Plant Breeding, Faculty of Agriculture, BAU, Mymensingh and *Corresponding author's E-mail: sharfuddin.grs@brri.gov.bd 
Genetic diversity is the foundation for an efficient choice of parents for the variety development programme. Genetic diversity is a powerful tool to determine the genetic discrimination among the genotypes, which is used to select appropriate parents for hybridization to develop high yielding potential variety (Bhatt, 1970). But limited work has been done on analysis of the genetic divergence for Balam rice of Bangladesh.

The present study was, therefore, undertaken to assess the extent of genetic diversity in Balam rice germplasm of Bangladesh for selecting genotypes as prospective parents to develop transgressive segregants.

\section{MATERIALS AND METHODS}

Forty genotypes of Balam rice germplasm of Bangladesh were selected and collected from BRRI Genebank, Gazipur and were studied for 13 agro-morphological and four physicochemical characters (Table 1). Thirty-day-old single seedling was transplanted per hill of each genotype for agro-morphological study during T. Aman 2009 and 2011 seasons. Spaces within and between rows were 20 and $25 \mathrm{~cm}$ respectively. The chemical fertilizer dose of 50 $40-10 \mathrm{~kg}$ PKS per hectare along with $60 \mathrm{~kg} N$ per hectare was applied. Total amount of TSP, MP and gypsum were applied at the final land preparation. Urea was applied in three installments at 15,30 and 45 days after transplanting (DAT). Nine plants from each entry were randomly selected for recording data on seedling height, flag and penultimate leaf area, plant height, culm diameter, effective tiller number per hill, days to maturity, primary and secondary branch number per panicle, average filled grain number per primary and secondary branches, grain yield per panicle, grain length, 1000-grain weight, straw and grain yield per hill. Besides, milling outturn, cooking time, protein and amylose content were measured according to the laboratory manual, GQND, BRRI during 2011. Genetic diversity was worked out following Mahalanobis' (1936) generalized distance $\left(\mathrm{D}^{2}\right)$ analysis extended by Rao (1952). Multivariate analyses were performed using GENSTAT 5.13 programme.

Table 1. The list of 40 Balam rice germplasm with BRRI accession number.

\begin{tabular}{|c|c|c|c|c|}
\hline $\begin{array}{l}\text { Common/ } \\
\text { Local name }\end{array}$ & $\begin{array}{l}\text { Code } \\
\text { name }\end{array}$ & Accession number & Place of collection & $\begin{array}{l}\text { Growing } \\
\text { season }\end{array}$ \\
\hline Balam & B1 & 1430 & Dhaka & T. Aman \\
\hline Balam & B2 & 995 & Khulna & Aus \\
\hline Balam & B3 & 516 & Rangpur & T. Aman \\
\hline Balam & B4 & 841 & Sylhet & Aus \\
\hline Balam & B5 & 4050 & M.Bazar & T. Aman \\
\hline Balam & B6 & 692 & Comilla & T. Aman \\
\hline Balam & B7 & 853 & Khulna & Aus \\
\hline Balam & B8 & 3643 & Pabna & T. Aman \\
\hline Balam & B9 & 843 & Sylhet & T. Aman \\
\hline Balam & B10 & 3516 & Rajshahi & Aus \\
\hline Balam & B11 & 683 & Comilla & T. Aman \\
\hline Balam & B12 & 720 & Comilla & B. Aman \\
\hline Balam & B13 & 855 & Sylhet & Aus \\
\hline Balam & B14 & 4045 & Kushtia & Aus \\
\hline Balam & B15 & 842 & Sylhet & T. Aman \\
\hline Balam & B16 & 823 & Sylhet & T. Aman \\
\hline Balam & B17 & 1013 & Khulna & T. Aman \\
\hline Balam & B18 & 839 & Sylhet & Aus \\
\hline Banaful Balam & B19 & 4164 & Jessor & T. Aman \\
\hline Baulam & B20 & 3565 & Barisal & Aus \\
\hline Baulam & B21 & 3730 & Barisal & Aus \\
\hline Beti Balam & B22 & 1011 & Khulna & T. Aman \\
\hline Bhua Balam & B23 & 878 & Sylhet & T. Aman \\
\hline Boilam & B24 & 3538 & Noakhali & Aus \\
\hline Boilam & B25 & 4608 & Noakhali & Aus \\
\hline
\end{tabular}


Bangladesh Rice J. 19(1): 9 - 15, 2015

\begin{tabular}{ccc} 
Boislam & B26 & 3201 \\
Boislam & B27 & 3497 \\
Bola Balam & B28 & 4836 \\
Jesso Balam TAPL & B29 & 2456 \\
Kabra Balam & B30 & 240 \\
Kartik Balam & B31 & 696 \\
Khud Balam & B32 & 3668 \\
Khud Balam & B33 & 2089 \\
Lal Balam & B34 & 2115 \\
Lona Balam & B35 & 4789 \\
Makai Balam & B36 & 4158 \\
Mogai Balam & B37 & 965 \\
Murki Balam & B38 & 771 \\
Patni Balam & B39 & 4838 \\
Samriti Balam & B40 & 3670 \\
\hline
\end{tabular}

$\begin{array}{cc}\text { Dhaka } & \text { Aus } \\ \text { Chittagong } & \text { Aus } \\ \text { Satkhira } & \text { T. Aman } \\ \text { PB, BRRI } & \text { T. Aman } \\ \text { Mymensingh } & \text { T. Aman } \\ \text { Comilla } & \text { B. Aman } \\ \text { Sherpur } & \text { T. Aman } \\ \text { Jamalpur } & \text { Aus } \\ \text { Dhaka } & \text { Aus } \\ \text { Satkhira } & \text { T. Aman } \\ \text { M. Bazar } & \text { T. Aman } \\ \text { Khulna } & \text { Aus } \\ \text { Chittagong } & \text { T. Aman } \\ \text { Satkhira } & \text { T. Aman } \\ \text { Jamalpur } & \text { T. Aman }\end{array}$

\section{RESULTS AND DISCUSSION}

Table 2 presents eigen values (latent roots) and percentage of total variation accounted for them obtained from principal component analysis (PCA). The result revealed that the first five components in the PCA with eigen values $>1$, contributed $77.43 \%$ of the total variations among the genotypes for 17 morpho-physicochemical characters. Sohrabi et al. (2012) and Chakravorty et al. (2013) observed the contribution of 76.7 and $75.9 \%$ of the first six and four components respectively to the total variation in rice. On the other hand, Hossain (2008) observed that the first eight axes accounted for about $90 \%$ of the total variations by PCA in 78 aromatic and fine grain rice landraces.

Table 2. Latent roots (Eigen value) and their variation for 17 morpho-physicochemical characters of 40 Balam rice germplasms.

\begin{tabular}{c|c|c|c}
\hline Principal component axes & Latent root & Variation accounted $(\%)$ & Cumulative variation \\
\hline I & 6.5278 & 38.40 & 38.40 \\
II & 2.0587 & 12.11 & 50.51 \\
III & 1.7933 & 10.55 & 61.06 \\
IV & 1.4885 & 8.76 & 69.82 \\
V & 1.2940 & 7.61 & 77.43 \\
VI & 0.9941 & 5.85 & 83.28 \\
VII & 0.7496 & 4.41 & 87.69 \\
VIII & 0.5897 & 3.47 & 91.16 \\
IX & 0.4392 & 2.58 & 93.74 \\
X & 0.3143 & 1.85 & 95.59 \\
XI & 0.2457 & 1.45 & 97.04 \\
XII & 0.1478 & 0.87 & 97.91 \\
XIII & 0.1184 & 0.70 & 98.61 \\
XIV & 0.0899 & 0.53 & 99.14 \\
XV & 0.0701 & 0.41 & 99.55 \\
XVI & 0.0526 & 0.31 & 99.86 \\
XVII & 0.0262 & 0.15 & 100.00 \\
\hline
\end{tabular}

The 40 genotypes of Balam rice germplasm were grouped into seven clusters on the basis of nonhierarchal clustering method using Mahalanobis' $\mathrm{D}^{2}$ statistics for 17 morphophysicochemical characters (Table 3). Sohrabi et al. (2012) reported six clusters in 50 Malaysian upland rice accessions for 12 growth traits, yield and yield components. Roy et al. (2004) found five clusters from 35 Aman rice cultivars for 10 traits during Kharif season and Datt et al. (2003) observed four clusters from 61 elite Basmati rice genotypes by using Mahalanobis' $\mathrm{D}^{2}$ statistics. But, Mahalingam et al. (2012) observed 13 clusters in 31 Indian and exotic germplasm lines. 
The distribution pattern of cluster indicated that the highest number of genotypes (8) included in clusters I, III and V, followed by clusters VI and VII respectively, while the lowest number of genotypes (2) included in cluster II. It also revealed that no duplicate existed among the genotypes for the studied characters. Fukuoka et al. (2006), Hossain (2008), Sarhadi et al. (2009) and Nascimento et al. (2011) earlier also found no duplicates from cluster analysis using Mahalanobis' $\mathrm{D}^{2}$ statistics in rice. The clustering pattern also revealed that the genotypes constellated in the cluster were not originated from the same geographic region. Chakravorty et al. (2013) by evaluating 51 rice land races, Hosan et al. (2010) by studying 20 landraces,
Rajesh et al. (2010) by assessing 29 land races and Medhabati et al. (2013) by studying 37 wild and cultivated rice also found no parallel relationship between genetic and geographical divergence. Based on the values of principal component score 1 and 2 obtained from the PCA, a two-dimensional scatter diagram $\left(Z_{1}-Z_{2}\right)$ (Fig. 1) using component score 1 as $X$-axis and component score 2 as Y-axis was constructed. The position of the genotypes in the scatter diagram was apparently distributed into seven groups indicating the existence of considerable diversity among the genotypes. The clustering pattern confirmed the results obtained by divergence analysis.

Table 3. Distribution of 40 Balam rice germplasms into seven clusters for 17 morpho-physicochemical characters.

\begin{tabular}{c|c|l}
\hline Cluster & No. of genotype & \multicolumn{1}{c}{ Name of genotype } \\
\hline I & 8 & B3, B5, B11, B22, B29, B36, B38, B39 \\
II & 4 & B9, B10, B28, B35 \\
III & 8 & B1, B4, B12, B13, B19, B23, B34, B37 \\
IV & 2 & B17, B18 \\
V & 8 & B7, B16, B20, B24, B25, B26, B27, B40 \\
VI & 5 & B2, B6, B8, B30, B32 \\
VII & 5 & B14, B15, B21, B31, B33 \\
\hline
\end{tabular}

Table 4 presents the average intra-(bold) and inter-cluster distances $\left(\mathrm{D}^{2}\right)$. The intra-cluster distance was maximum (1.17) in cluster VII and minimum (0.27) in cluster IV, denoting that the genotypes under cluster VII were the most diverse and those of cluster IV were comparatively similar or less diverse than the genotypes of other clusters. Regarding the intercluster distance, maximum genetic distance (21.16) was observed between the clusters II and
IV indicating wide range of diversity, while the minimum inter-cluster distance (2.23) was observed between the clusters II and VII. Mahalingam et al. (2012) found inter cluster distance ranged from 6.14 to 24.84 , higher than intra cluster distance that ranged from 0.0 to 12.11 for Indian and exotic rice. Hossain (2008) reported intra- and inter-cluster distance ranged from 0.0 to 1.02 and 2.21 to 21.59 respectively on aromatic and fine grain land races of rice.

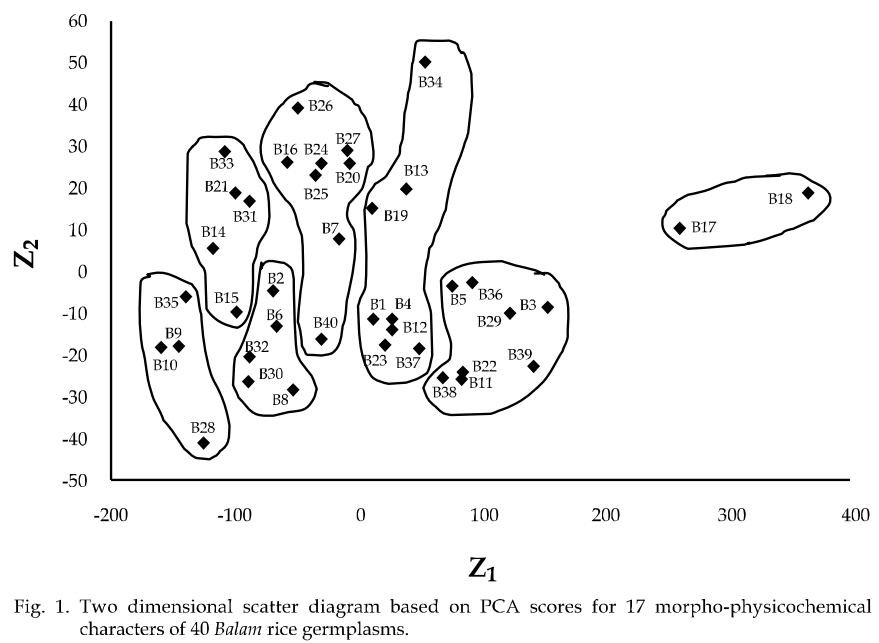


Table 4. Average intra-(bold) and inter-cluster distances $\left(D^{2}\right)$ for 17 morpho-physicchemical characters of 40 Balam rice germplasms.

\begin{tabular}{c|c|c|c|c|c|c|c}
\hline Cluster & I & II & III & IV & V & VI & VII \\
\hline I & $\mathbf{0 . 6 9}$ & & & & & & \\
II & 11.54 & $\mathbf{1 . 1 5}$ & & & & & \\
III & 3.95 & 7.60 & $\mathbf{1 . 0 1}$ & & & & \\
IV & 11.85 & 21.16 & 14.74 & $\mathbf{0 . 2 7}$ & & & \\
V & 8.26 & 5.61 & 5.13 & 15.86 & $\mathbf{0 . 9 9}$ & & \\
VI & 8.15 & 3.54 & 4.23 & 18.57 & 4.64 & $\mathbf{0 . 7 1}$ & \\
VII & 10.19 & 2.23 & 6.35 & 19.12 & 3.40 & 3.18 & $\mathbf{1 . 1 7}$ \\
\hline
\end{tabular}

Table 5 presents the mean values for all cluster IV are crossed with the genotypes the 17 morpho-physicochemical of cluster I, cluster III and cluster VI characters. The data revealed that different respectively. Hosan et al. (2010), clusters exhibited the highest and lowest Mahalingam et al. (2012), Sohrabi et al. mean values of individual characters and (2012) and Medhabati et al. (2013) earlier none of the clusters showed the highest or reported similar trend of conclusions on lowest mean values of all the characters. rice using Mahalanobis' $\mathrm{D}^{2}$ statistics.

However, the genotype of cluster IV with the cumulative ranking 1 , produced the highest flag and penultimate leaf area $\left(1136 \mathrm{~cm}^{2}\right)$, culm diameter $(7.2 \mathrm{~mm})$, days to maturity (152 days), primary and secondary branch number per panicle (63), grain yield per panicle (4.9 g), 1000-grain weight $(29.3 \mathrm{~g})$, grain yield per hill (31.3 g), cooking time (19 $\mathrm{min}$ ) and amylose content $(24.1 \%)$. Similarly, the genotype of cluster I with the cumulative ranking 2, produced the tallest plant $(148 \mathrm{~cm})$ and maximum straw yield per hill (40.0 g) and protein content $(9.6 \%)$, while the genotype of cluster VI with the cumulative ranking 3 , produced the highest effective tiller number per plant (21) and the genotype of cluster III with the cumulative ranking 4 produced the longest grain $(8.8 \mathrm{~mm})$. Therefore, it may be possible to obtain the highest mean values for the maximum studied characters, if the genotypes of

In the present study, it was also appeared from the canonical analysis that $73.85 \%$ of the total variation was accounted for canonical root 1 and $15.71 \%$ by canonical root 2 (Table 6). Table 7 presents the coefficients pertaining to the different characters in the first two canonical roots. It was revealed from canonical variate analysis that grain length, cooking time, straw yield per hill, days to maturity, plant height and grain yield per panicle were the most responsible for both the primary and secondary differentiations and contributed maximum to the genetic divergence for the characters of the germplasm studied. Earlier, Mahalingam et al. (2012) and Rajesh et al. (2010) found similar results. However, the above result was in agreement with earlier reports in rice by Hossain (2008) and Hosan et al. (2010).

Table 5. Cluster means of 40 Balam rice germplasm for $\mathbf{1 7}$ morpho-physicochemical characters.

\begin{tabular}{|c|c|c|c|c|c|c|c|c|c|c|c|c|c|c|c|c|c|c|}
\hline 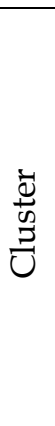 & 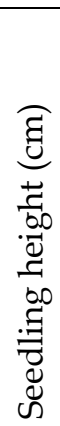 & 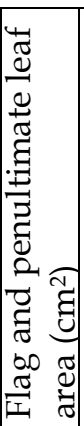 & 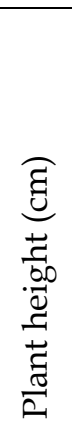 & 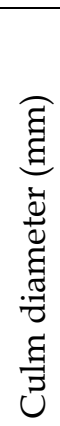 & 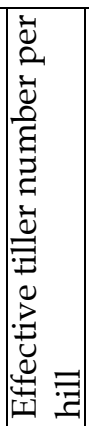 & 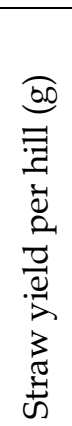 & 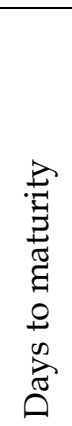 & 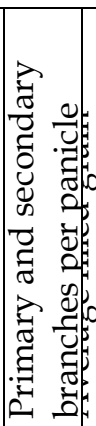 & 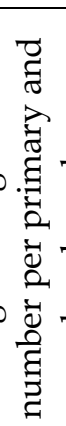 & 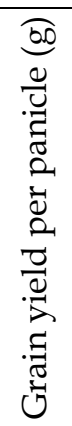 & 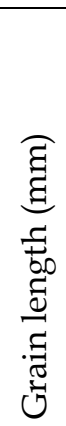 & 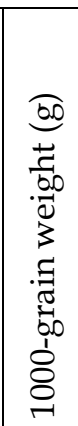 & 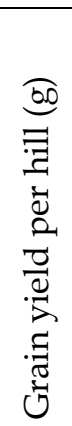 & 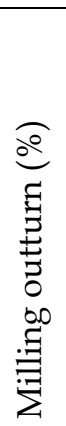 & 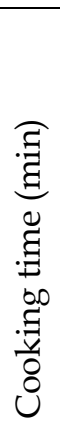 & 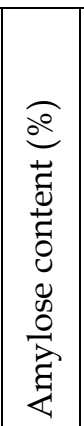 & 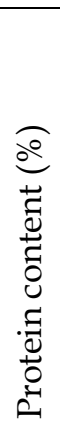 & 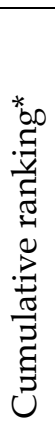 \\
\hline 1 & 65 & 924 & 148 & 6.2 & 15 & 40.0 & 151 & 51 & 7.2 & 3.4 & 8.5 & 23.2 & 6.0 & 70 & 19 & 22.3 & 9.6 & \\
\hline II & 66 & 680 & 119 & 4.9 & 18 & 26.5 & 139 & 34 & 6.9 & 2.5 & 8.5 & 24.3 & 23.6 & 70 & 18 & 23.1 & 8.6 & \\
\hline
\end{tabular}




\begin{tabular}{lcccccccccccccccccc} 
III & 60 & 854 & 127 & 5.3 & 15 & 30.6 & 142 & 41 & 6.9 & 2.5 & 8.8 & 22.4 & 23.0 & 68 & 18 & 21.7 & 9.1 & 4 \\
IV & 64 & 1136 & 141 & 7.2 & 9 & 34.4 & 152 & 63 & 7.2 & 4.9 & 8.3 & 29.3 & 31.3 & 70 & 19 & 24.1 & 8.6 & 1 \\
V & 64 & 798 & 110 & 4.8 & 14 & 17.2 & 133 & 29 & 7.4 & 2.2 & 8.3 & 24.1 & 16.9 & 69 & 18 & 22.1 & 8.9 & 7 \\
VI & 62 & 748 & 131 & 5.4 & 21 & 28.6 & 147 & 44 & 6.9 & 2.7 & 8.6 & 21.2 & 25.7 & 68 & 17 & 22.6 & 9.6 & 3 \\
VII & 54 & 724 & 104 & 4.9 & 13 & 20.0 & 133 & 37 & 7.5 & 2.3 & 8.1 & 20.1 & 15.7 & 70 & 18 & 23.5 & 9.1 & 6 \\
\hline
\end{tabular}

Table 6. Values of canonical roots and percentage of variation of 17 morpho-physicochemical characters of 40 Balam rice germplasms.

\begin{tabular}{c|c|c}
\hline Canonical root & $\begin{array}{c}\text { Values of the } \\
\text { canonical root }\end{array}$ & \% of variation absorbed by the canonical root \\
\hline 1 & 28.53 & 73.85 \\
2 & 6.07 & 15.71 \\
3 & 1.96 & 5.08 \\
4 & 1.23 & 3.18 \\
5 & 0.47 & 1.21 \\
6 & 0.38 & 0.98 \\
\hline Total & & 100.0 \\
\hline
\end{tabular}

Table 7. Latent vectors for 17 morpho-physicochemical characters of 40 Balam rice germplasms.

\begin{tabular}{l|c|c|c}
\hline \multicolumn{1}{c|}{ Character } & Vector I & Vector II & Combined ranking \\
\hline Seedling height $(\mathrm{cm})$ & +0.0089 & -0.0743 & 9 \\
Flag and penultimate leaf area $\left(\mathrm{cm}^{2}\right)$ & -0.0413 & -0.0157 & 8 \\
Plant height $(\mathrm{cm})$ & -0.0228 & +0.0940 & $\mathbf{5}$ \\
Culm diameter (mm) & -0.6004 & +0.0651 & 14 \\
Effective tiller number per hill & -0.0204 & -0.0569 & 10 \\
Straw yield per hill (g) & +0.0017 & +0.1988 & $\mathbf{3}$ \\
Days to maturity & +0.0095 & +0.0775 & $\mathbf{4}$ \\
Primary and secondary branch number & +0.0074 & -0.0556 & 7 \\
per panicle & & & \\
Average filled grain number per primary & +0.0875 & -0.6988 & 16 \\
and secondary branches & & & \\
Grain yield per panicle (g) & -0.1799 & +0.1988 & $\mathbf{6}$ \\
Grain length (mm) & +0.4411 & +0.3270 & $\mathbf{1}$ \\
1000-grain weight (g) & -0.0193 & -0.2049 & 13 \\
Grain yield per hill (g) & +0.0321 & -0.2122 & 11 \\
Milling outturn (\%) & -0.0148 & -0.6437 & 17 \\
Cooking time (min) & -0.0241 & +0.7290 & $\mathbf{2}$ \\
Amylose content $(\%)$ & +0.0161 & -0.1970 & 12 \\
Protein content $(\%)$ & -0.0503 & -0.5521 & 15 \\
\hline Coming & &
\end{tabular}

${ }^{*}$ Combined ranking is estimated by summing the values of vector I and II, then higher (1) is the rank with higher positive value.

\section{CONCLUSIONS}

The highest genetic diversity was existed between the genotypes of clusters II and IV. The genotype of cluster IV produced the highest flag and penultimate leaf area, culm diameter, days to maturity, primary and secondary branches per panicle, grain yield per panicle, 1000-grain weight, grain yield per hill, cooking time and amylose content. On the other hand, cluster I produced the tallest plant along with maximum straw yield per hill and protein content, while cluster VI produced the highest panicle per plant and cluster III 
produced the longest grain. Therefore, it may be possible to obtain Balam rice with maximum good characters, if the genotypes of cluster IV are crossed with the genotypes of cluster I, cluster III and cluster VI.

\section{ACKNOWLEDGEMENTS}

This study was a part of the corresponding author's PhD dissertation and he acknowledges the financial support and research facilities of Genetic Resources and Seed Division of Bangladesh Rice Research Institute, Gazipur 1701.

\section{REFERENCES}

Ahmed, M S, K Akter, M Khalequzzaman, E S M H Rashid and M K Bashar. 2010. Diversity analysis in Boro rice (Oryza sativa L.) accessions. Bangladesh J. Agril. Res. 35 (1): 29-36.

Bhatt, G M. 1970. Multivariate analysis approach to selection of parents of hybridization aiming at yield improvement in self-pollinated crops. Aust. J. Agric. Res. 21: 1-7.

Chakravorty, A, P D Ghosh, P K Sahu. 2013. Multivariate analysis of phenotypic diversity of landraces of rice of West Bengal. American J. Exp. Agric. 3(1): 110-23.

Datt, S, S C Mani, S Datt. 2003. Genetic divergence in elite genotypes of Basmati rice (Oryza sativa L.). Indian J. Genet. Plant Breed. 63(1): 73-74.

Fukuoka, S, T D Suu, K Ebanna, L N Trinh. 2006. Diversity in phenotypic profiles in landraces populations of Vietnamese rice: A case study of agronomic characters for conserving crop genetic diversity on farm. Genetic Resources Crop Evol. 53: 753761.

Hosan, S M, N Sultana, K M Iftekharuddaula, M N U Ahmed, S Mia. 2010. Genetic Divergence in Landraces of Bangladesh Rice (Oryza sativa L.). The Agriculturists, 8(2): 2834.

Hossain, M Z. 2008. Genetic diversity study in fine grain and aromatic landraces of rice (Oryza sativa L.) by morpho-physico-chemical characters and micro-satellite DNA markers, $\mathrm{PhD}$ thesis, Department of Genetics and Plant Breeding, BSMRU, Gazipur, Bangladesh.

Jayamani, P, S Negrao, M Martins, B Macas, M M Oliveira. 2007. Genetic relatedness of Portuguese rice accessions from diverse origins as assessed by microsatellite markers. Crop Sci. 47(2): 879-886.

Mahalanobis, P C. 1936. On the generalized distance in statistics. Nat. Inst. Sci. India Bull. 2: 49-55.

Mahalingam, A, R Saraswathi, J Ramalingam, T Jayaraj. 2012. Genetic studies on divergence and phenotypic characterization of indigenous and exotic indica germplasm lines in rice (Oryza sativa L.). African J. Agric. Res. 7(20): 3120-28.

Medhabati, K, M Rohinikumar, H Sunitibala, T D Singh. 2013. Genetic divergence in indigenous wild and cultivated rice species of Manipur valley. ISRN Genetics, 2013: 1-6.

Nascimento, W F, E F Silva, E A Veasey. 2011. Agro-morphological characterization of upland rice accessions. Sci. Agric. 68(6): 652-60.

Rajesh, T, K Paramasivam, S Thirumeni. 2010. Genetic divergence in land races of rice. Electronic J. Plant Breeding, 1(2): 199-204.

Rao, C R. 1952. Advance statistical methods in Biometrical Research. John Willey and Sons Inc., New York, USA. p. 45-110.

Roy, S K, A Kundu, S P Chand, B K Senapati. 2004. Diversity of panicle characters in Aman rice (Oryza sativa L). Environ. Ecol. 22(Spl-3): 500-503.

Sarhadi, W A, T Ookawa, T Yoshihashi, A K Madadi, W Yosofzai, Y Oikawa, Y Hirata. 2009. Characterization of aroma and agronomic traits in Afghan native rice cultivars. Plant Production Sci. 12: 63-69.

Sarma, M K, A K Richharia and P K Agrawal. 2003. Pattern of pigmentation in Ahu Rices of Assam. Indian J. Plant Gen. Resource, 16: 3539.

Sohrabi, M, M Y Rafii, M M Hanafi, A S N Akmar, M A Latif. 2012. Genetic Diversity of upland rice germplasm in Malaysia Based on Quantitative Traits. The Scientific World J. 416291: 1-9. 